\title{
GEOSSISTEMAS DE CURAÇÁ, BAHIA
}

\section{GEOSYSTEMS OF CURAÇÁ, BAHIA}

\author{
Lucas Costa de Souza Cavalcanti ${ }^{1}$ \\ lucascavalcanti3@gmail.com
}

\begin{abstract}
Aiming to represent diversity of natural landscapes, geosystems mapping can help with the understanding of prehistoric sites. This work aimed at mapping the geosystems of the municipality of Curaçá, located in the north of the State of Bahia, on the right bank of the São Francisco River. The map was elaborated based on groups of landscape facies. A fragment of the geosystems map is presented in this article, highlighting the central area of the municipality.
\end{abstract}

Keywords: Prehistoric sites, Geosystems Mapping, Brazilian semi-arid.

\footnotetext{
${ }^{1}$ Docente, Departamento de Ciências Geográficas, UFPE.
} 


\section{RESUMO}

Visando representar a diversidade da organização natural das paisagens, a cartografia de geossistemas pode auxiliar a compreensão de sítios de ocupação pré-histórica. Este trabalho teve como objetivo mapear os geossistemas do município de Curaçá, localizado no Estado da Bahia, à margem direita do Rio São Francisco. O mapa foi elaborado a partir da identificação de grupos de fácies. É apresentado um fragmento do mapa de geossistemas com destaque para a parte central do município.

Palavras-chave: Cenários de ocupação, Cartografia de geossistemas, Semiárido Brasileiro.

\section{CONTEXTO DA PESQUISA}

Sítios de ocupação pré-histórica nem sempre apresentam condições ambientais semelhantes às do presente. Todavia, a diferenciação de ambientes atuais é fundamental para uma compreensão abrangente das mudanças ambientais e reconstrução de cenários de ocupação pretéritos.

A cartografia de paisagens (geossistemas) é uma ferramenta para diferenciação de ambientes. Consiste na diferenciação e representação de áreas conforme estruturas e padrões de funcionamento. $\mathrm{O}$ desenvolvimento desta atividade remonta às ideias de Humboldt e à doutrina das zonas naturais de Dokuchaev (CAVALCANTI; CORRÊA, 2014). Estas propostas estão relacionadas à diferenciação da superfície terrestre em regiões homogêneas em função do conjunto de seus elementos e processos naturais.

A principal utilidade deste tipo de produto é que ele informa sobre ambientes diferentes em termos de condições ecológicas, hidrológicas, pedológicas e 
geomorfológicas. O grande desafio jaz na representação cartográfica destas áreas, sobretudo na escolha das/variáveis que vão compor as unidades a serem mapeadas.

Um dos principais métodos para identificação de geossistemas baseia-se na ideia de fatores condicionantes. Estes fatores consistem de padrões e processos ambientais que constrangem o desenvolvimento de geossistemas em seu interior, limitando os graus de liberdade dos processos ecológicos.

Por exemplo, estudando a temperatura de germinação de 30 espécies de cactos do semiárido brasileiro (MEIADO et al, 2015) descobriu que nenhuma delas germinava abaixo de $10^{\circ} \mathrm{C}$. Deste modo, ambientes microtérmicos seriam uma limitação ao desenvolvimento de tais cactos. Em outro exemplo, planossolos, gleissolos e vertissolos possuem sua pedogênese associada à estagnação de água num local mais baixo, dificilmente sendo encontrados nos regimes geoquímicos de oxidação de alta encosta.

A busca por fatores condicionantes é/ uma das principais atividades que fundamentam a cartografia de geossistemas. Alguns princípios relacionados ao método dos fatores condicionantes estão sumarizados abaixo: 
1. Muitos sistemas ecológicos podem conviver num mesmo local, variando apenas com/base na escala do observador, o que impossibilitaria sua representação espacial. Todavia, estes diferentes ecossistemas estariam sujeitos a um mesmo conjunto de fatores condicionantes que encadeiam as relações ecológicas numa determinada área (BRIERLEY; FRYIRS, 2005; BAILEY, 2009);

2. As fronteiras entre diferentes geossistemas estão em constante variação. Contudo, as modificações destas fronteiras estariam dentro dos limites impostos por fatores condicionantes, como por exemplo, a fenologia (ISACHENKO, 2007; BAILEY, 2009);

3. A interação entre os organismos pode gerar diferentes padrões espaciais independentemente das variações abióticas. Estas variações, porém, estariam dentro do limite de fatores condicionantes com dimensões superiores (SOCHAVA, 1977; 1978; BAILEY, 2009).

Deste modo, um geossistema pode ser definido como uma porção do espaço terrestre em que diferentes elementos e processos naturais interagem sob determinadas condições. Estas condições restringem as possibilidades de funcionamento e desenvolvimento dos geossistemas. Deste modo geossistemas podem ser entendidos como sistemas dinâmicos, abertos e hierarquicamente organizados (SOCHAVA, 1977; CAVALCANTI; CORRÊA, 2016).

Estudar geossistemas é pensar sobre como a organização natural de elementos e processos ambientais em interação promove o surgimento de padrões fisionômicos e funcionais dinâmicos. Este conhecimento, estritamente físicogeográfico de interface, é importante para decisões sobre o uso da terra e possui 
quatro direcionamentos complementares: estrutural, funcional, evolutivo e as derivações de origem social (antropogênicas).

O direcionamento estrutural busca a compartimentação dos geossistemas pela observação do arranjo espacial de seus componentes. A dinâmica dos geossistemas foca no estudo da transformação da energia e circulação e transformação da matéria nos geossistemas, considerando o balanço de radiação e de energia, balanço hídrico, produtividade de biomassa, decomposição da matéria orgânica, ciclagem de nutrientes, produção de sedimentos, fenofases, entre outros (ZUCHKOVA; RAKOVSKAIA, 2004).

O estudo direcionamento evolutivo se concentra na determinação de mudanças em patamares de estabilidade, na formação e sucessão de paleoambientes. Neste ponto, o significado de dados geomorfológicos, paleoclimáticos, paleopedológicos e paleobotânicos é complementar e fundamental para a construção de um modelo abrangente das complexas variações na trajetória dos geossistemas (CORRÊA, 2006).

Contemplando os aspectos estruturais, funcionais e evolutivos do estudo de geossistemas, percebe-se que o mesmo se situa na interface de conteúdos de outras áreas da Geografia, principalmente, a Geomorfologia, a Pedologia e a Biogeografia, dependendo delas, mas não se limitando a elas. 
Não obstante a demanda pelo conhecimento dos geossistemas, é preciso pensar também a sua interação com a sociedade. Neste sentido, o direcionamento antropogênico considera três aspectos: o primeiro deles diz respeito à avaliação do potencial (recursos e serviços ambientais) e limites que as diferentes formações naturais (geossistemas) oferecem à sociedade.

O segundo aspecto trata do modo como a sociedade, por meio do trabalho, impacta e transforma os geossistemas, afetando seu funcionamento, estabilidade e resiliência, a ênfase é na avaliação de impactos ambientais. O terceiro aspecto consiste em avaliar a sustentabilidade das ações da sociedade sobre os geossistemas, determinando as ações mais adequadas a serem tomadas, aborda entre outras coisas a previsão de impactos ambientais.

Passando do plano epistemológico para a demanda por identificação e cartografia de geossistemas (direcionamento estrutural), a prática exige a adoção de unidades de mapeamento que reflitam o funcionamento dos sistemas ambientais. A menor unidade reconhecida para o mapeamento de geossistemas é denominada fácies geográfica. Proposta na década de 1930 por Ramensky, refere-se a um segmento de relevo uniforme (em termos de litotipo, posição, forma, orientação e declive), apresentando um microclima e um regime de drenagem. Geralmente com um solo e uma associação de plantas (Figura 1). 

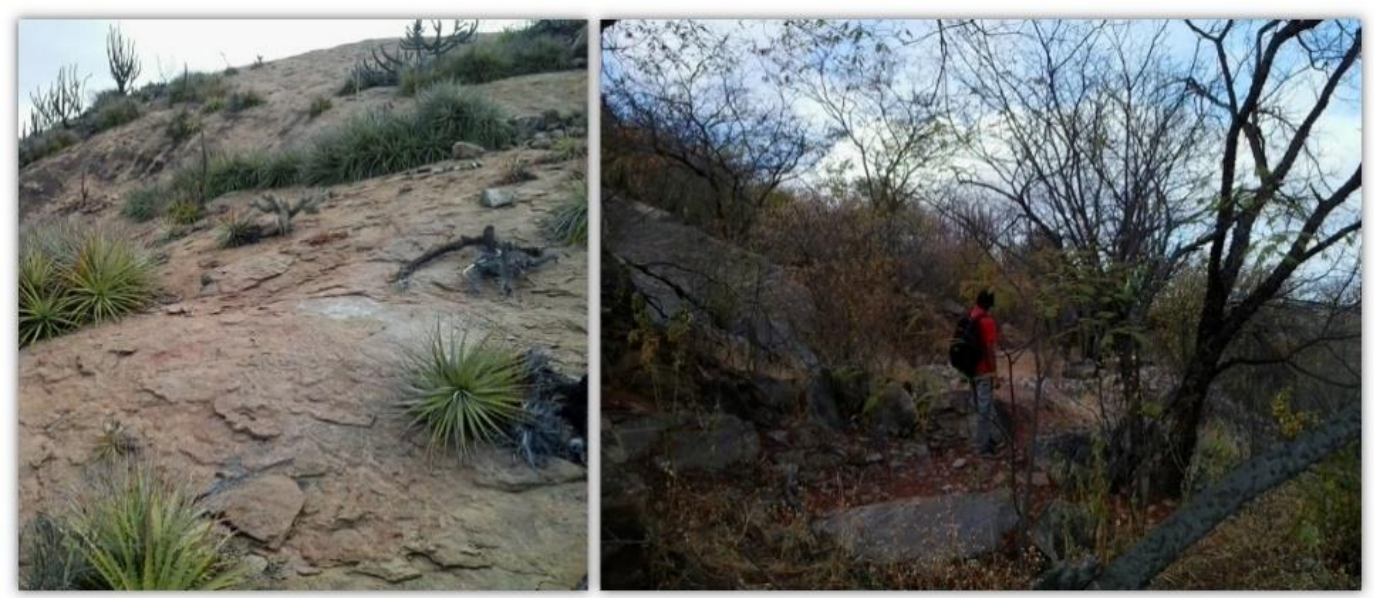

Figura 1: Dois Exemplos de Fácies Geográfica. Encosta rochosa com Encholirium spectabile e Facheiroa squamosa (esq.); Tálus com solos de textura média sob Anadenanthera colubrina.

Em função de seu tamanho reduzido, fácies são adequadas a mapeamentos em escalas grandes, tais como 1:5.000 ou maior, raramente 1:10.000 (ZUCHKOVA, RAKOVSKAIA, 2004). A cartografia de fácies é conduzida prioritariamente por meio de levantamentos de campo. É aplicável para planejamento detalhado do uso da terra.

Para escalas menores, visando o recobrimento de áreas maiores, o mapeamento de fácies é pouco usual, sobretudo por questões logísticas. Para áreas maiores, é adequado mapear grupos de fácies, que são definidos como o menor tipo de associação funcional entre fácies (SOCHAVA, 1978). 
A ideia de utilizar o grupo de fácies como táxon padrão para o mapeamento de geossistemas se fortaleceu entre geógrafos soviéticos, posteriormente aglutinando os grupos de fácies em categorias de geossistemas superiores (SEMENOV, SUVOROV, ANTIPOV, 2007).

Para identificação de um grupo de fácies Sochava destaca que "O interesse último está relacionado à situação no terreno e à vegetação" pois "Ambos os componentes são bem detectados à distância por fotografia" (SOCHAVA, 1978, p.227, tradução nossa).

Neste sentido, Lysanova; Semenov; Sorokovoi (2011, p.358, tradução nossa) reforçam que:

Grupos de fácies devem ser identificados no interior de uma superficie geneticamente uniforme, sendo diferenciados por sua localização próxima (encostas, encostas suaves, piemontes, etc.) com um regime de drenagem similar e com um grupo de associações de plantas (...)

Alguns exemplos de grupos de fácies incluem: Encostas com mescla de abetos, musgo e arbustos (SOCHAVA, 1978); Vale e planície de inundação com brejospradarias turfa-ciperáceas em solos aluviais; Encostas com Picea e grama fir em solos ácidos e terras marrons humilúvicas e; Encostas suaves com bétula e bétulaálamo estepisado combinado com pradarias e estepes em chernozems lixiviados (LYSANOVA; SEMENOV; SOROKOVOI 2011). 
O destaque do relevo como referência para a identificação de grupos de fácies não se dá por acaso. Para Tricart, "do ponto de vista ecológico, a morfodinâmica é uma limitação" (1977, p.29). Isto porque o desenvolvimento dos solos e a sucessão vegetacional se dão muito mais facilmente num contexto de estabilidade morfodinâmica. Logo, em certa medida, geossistemas encontram-se manifestos nas formas de relevo, não sendo, contudo, reduzidos a elas.

Além disso, formas de relevo são facilmente observáveis em fotografias aéreas, imagens de satélite e principalmente de radar. Deste modo, diversos autores incluíram o relevo, juntamente com a vegetação como elementos-chave do mapeamento ambiental integrado, caracterizando o que Verstappen (1977) denominou de mapas sintéticos. Exemplos desta proposta são os modelos de land systems da CSIRO australiana (CHRISTIAN; STEWART, 1952) e os geossistemas de Viktor B. Sochava (1978).

Não obstante os esforços de cartografia de geossistemas, a importância do relevo e seus atributos na previsão da ocorrência de outros componentes da natureza tem sido testada positivamente para solos, drenagem, geoquímica superficial e até em características hidrológicas, microclimáticas e vegetacionais (KHOROSHEV, 2010).

$\mathrm{Na}$ necessidade de suprir a demanda de informações da estrutura paisagística para a conservação da natureza, este trabalho teve como objetivo reconhecer aspectos 
gerais dos geossistemas do município de Curaçá, localizado no Estado da Bahia, à margem direita do Rio São Francisco.

\section{MATERIAIS E MÉTODOS}

O município de Curaçá (Figura 2) localiza-se na meso-região do Vale Sãofranciscano da Bahia, distando $587 \mathrm{~km}$ de Salvador e $631 \mathrm{~km}$ do Recife. Possui área de $6.442,19 \mathrm{~km}^{2}$ e cerca de 32 mil habitantes, caracterizando densidade demográfica de $\approx 5 \mathrm{hab} . / \mathrm{km}^{2}$. Os primeiros registros de penetração portuguesa datam de 1562, tendo sido constituído distrito em 1714 - inicialmente Pambú tornando-se cidade em 1832, passou a chamar-se Curaçá em 1890.

O município tem sido reconhecido pelo seu potencial para a conservação da natureza. Curaçá guarda registros históricos e relato recente (em 2016) da ocorrência da ararinha-azul (Cyanopsitta spixii, Wagler, 1832), considerada em perigo crítico de extinção. Em função da caatinga preservada, a área foi considerada como prioritária para a conservação da natureza pelo Zoneamento Ecológico-Econômico da Bahia (BAHIA, 2014). Não obstante, o potencial cuprífero da região pode vir a trazer dilemas para a decisão sobre o uso terra no futuro. Recentemente, tanto o governo da Bahia quanto o governo federal propuseram diferentes unidades de conservação para o município (ECOSSISTEMA, 2013). 


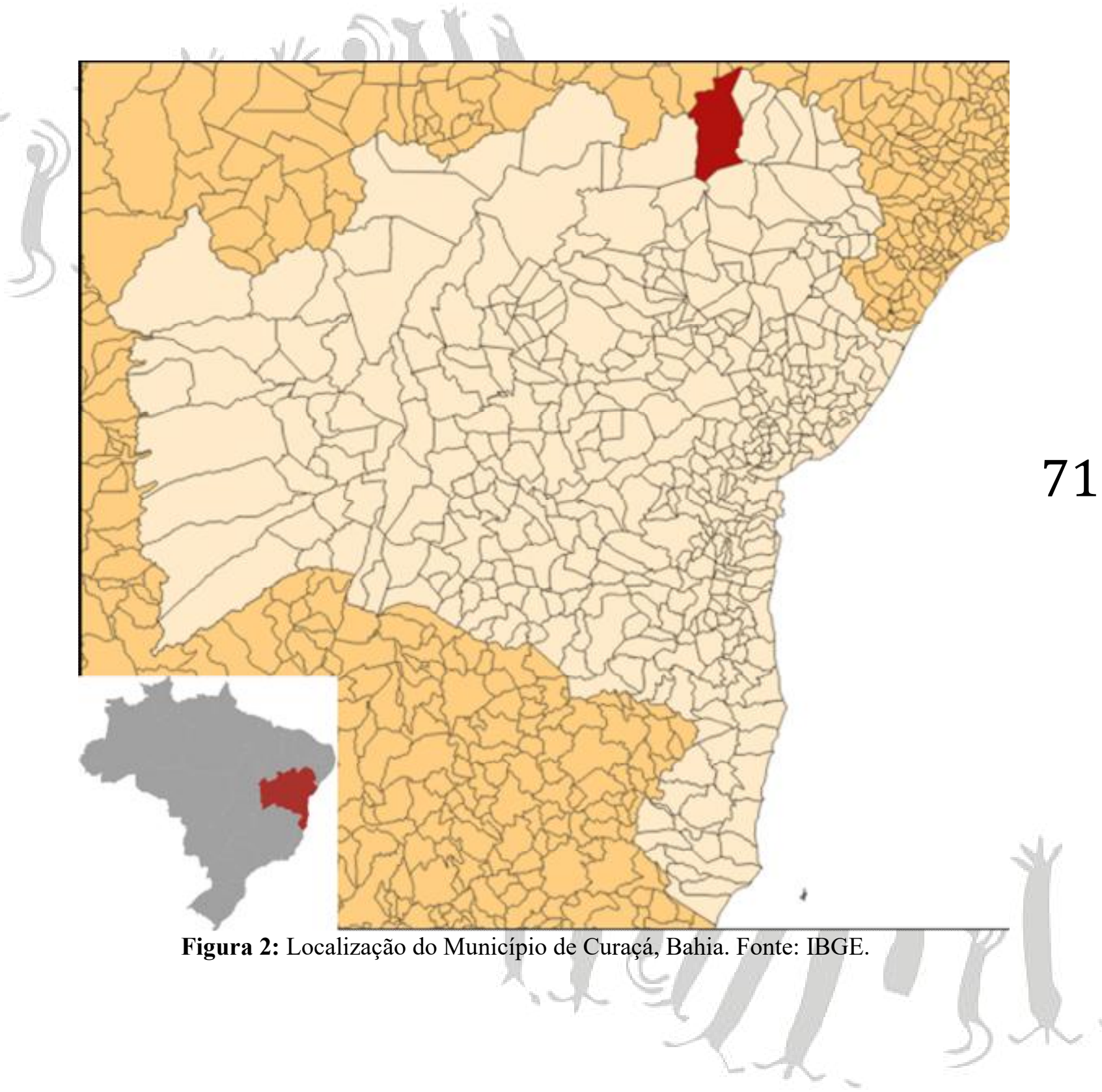


Visando auxiliar o reconhecimento das paisagens de Curaçá, foi elaborado um mapa dos geossistemas baseado nos seus grupos de fácies. O trabalho foi realizado em cinco etapas. O fluxograma da Figura 3 sumariza os procedimentos adotados.

\section{Revisão dos trabalhos anteriores}

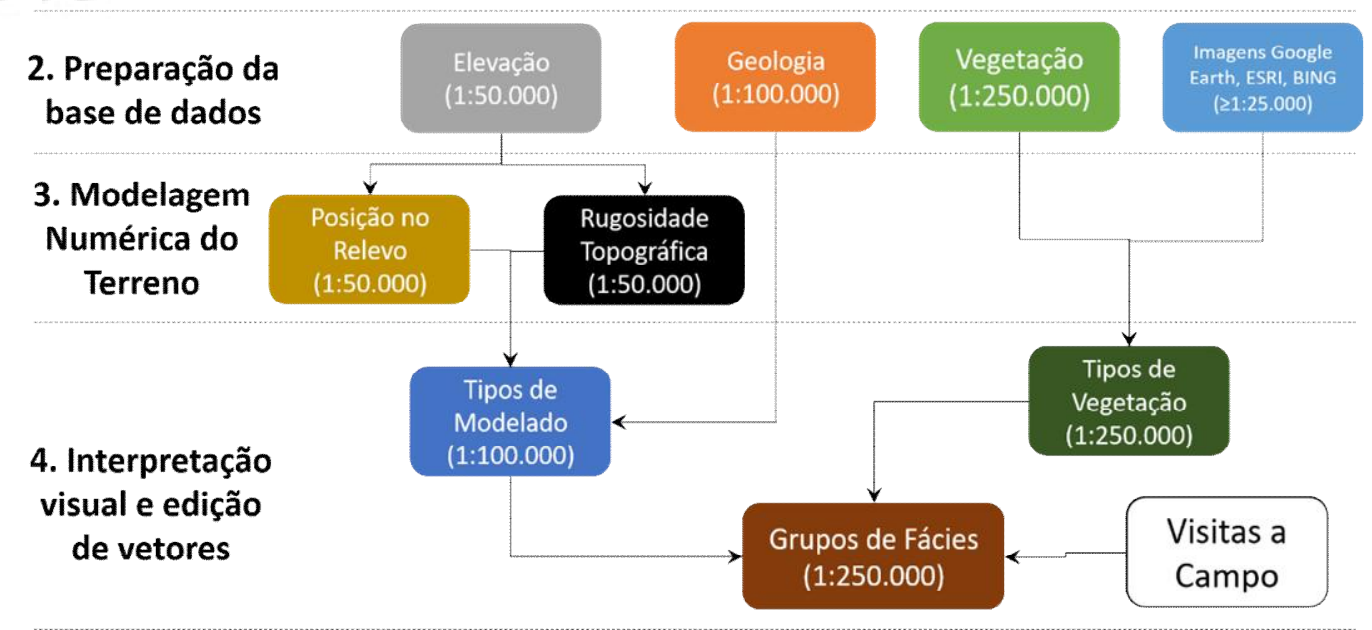

\section{Leiaute do Mapa, Preparação da Legenda e Elaboração do Relatório}

Figura 3: Fluxograma para o Mapeamento de Geossistemas.

Inicialmente foi realizada uma revisão dos trabalhos anteriores. Para legenda do mapa, escolheu-se indicar informações gerais sobre os tipos de modelado, solos e vegetação. Para tanto, foi reunida a melhor base de dados disponível. Para elevação foram utilizados dados SRTM com resolução espacial de 1 segundo de arco, (aproximadamente $30 \mathrm{mx} 30 \mathrm{~m}$ ), adequada a representação na escala 1:50.000. 
Também foram utilizados seis mapas geológicos na escala 1:100.000 (Folhas Chorrochó, Barro Vermelho, Macururé, Santa Maria da Boa Vista, Pinhões e Uauá).

Para interpretação da vegetação foram utilizados dados do mapa da vegetação do Ministério do Meio Ambiente (Folhas Uauá e Salgueiro - 1:250.000), cujos limites foram reinterpretados com auxílio de imagens de satélite disponibilizadas pelo Google Earth, ESRI e Bing, acessadas pelo plugin QuickMapServices do QGIS 2.14.

A partir dos dados de elevação foram elaborados modelos numéricos do terreno representando a posição no relevo e a rugosidade do terreno. Ambos os modelos foram elaborados utilizando as ferramentas do SAGA GIS disponíveis no QGIS 2.14. Os dados de posição e rugosidade, juntamente com a informação geológica, foram utilizados como base para interpretação visual dos tipos de modelados, baseando-se na tipologia proposta por Cavalcanti, Lira e Corrêa (2016).

As informações sobre as fitofisionomias foram adicionadas àquelas dos modelados para determinar os grupos de fácies. Neste sentido, algumas unidades do modelado, apresentando fitofisionomias diferentes, foram subdivididas. Neste sentido, os limites dos grupos de fácies foram determinados primariamente pelos tipos de modelados e, em seguida, modificados em função de variações na 
vegetação/cobertura da terra. A validação do modelo foi realizada com visitas a campo.

Optou-se por inferir as informações dos solos com base nas catenas típicas para o semiárido (CORRÊA; SOUZA; CAVALCANTI, 2014), isto porque o mapa de solos disponível era o do estado da Bahia (1:4.000.000). Nestes termos, foram adotados, quando possível, nomes mais gerais para descrever os solos em vez da nomenclatura do Sistema Brasileiro de Classificação de Solos.

Após a delimitação dos grupos de fácies, estes foram aglutinados em categorias de geossistemas superiores, buscando-se adequar a nomenclatura àquela da carta das paisagens do semiárido brasileiro (CAVALCANTI, 2016). Após a composição da legenda, o mapa final foi confeccionado para ser apresentado na escala 1:250.000 (impressão em A1). A escala adotada foi definida pela escala da base de dados com menor detalhamento que foi utilizada (vegetação).

\section{RESULTADOS E DISCUSSÕES:}

O mapeamento permitiu identificar 29 diferentes grupos de fácies, representando os principais conjuntos ambientais do município de Curaçá. Neste trabalho apresentamos 19 destes grupos em um fragmento de mapa da área central do município (Figura 4). 


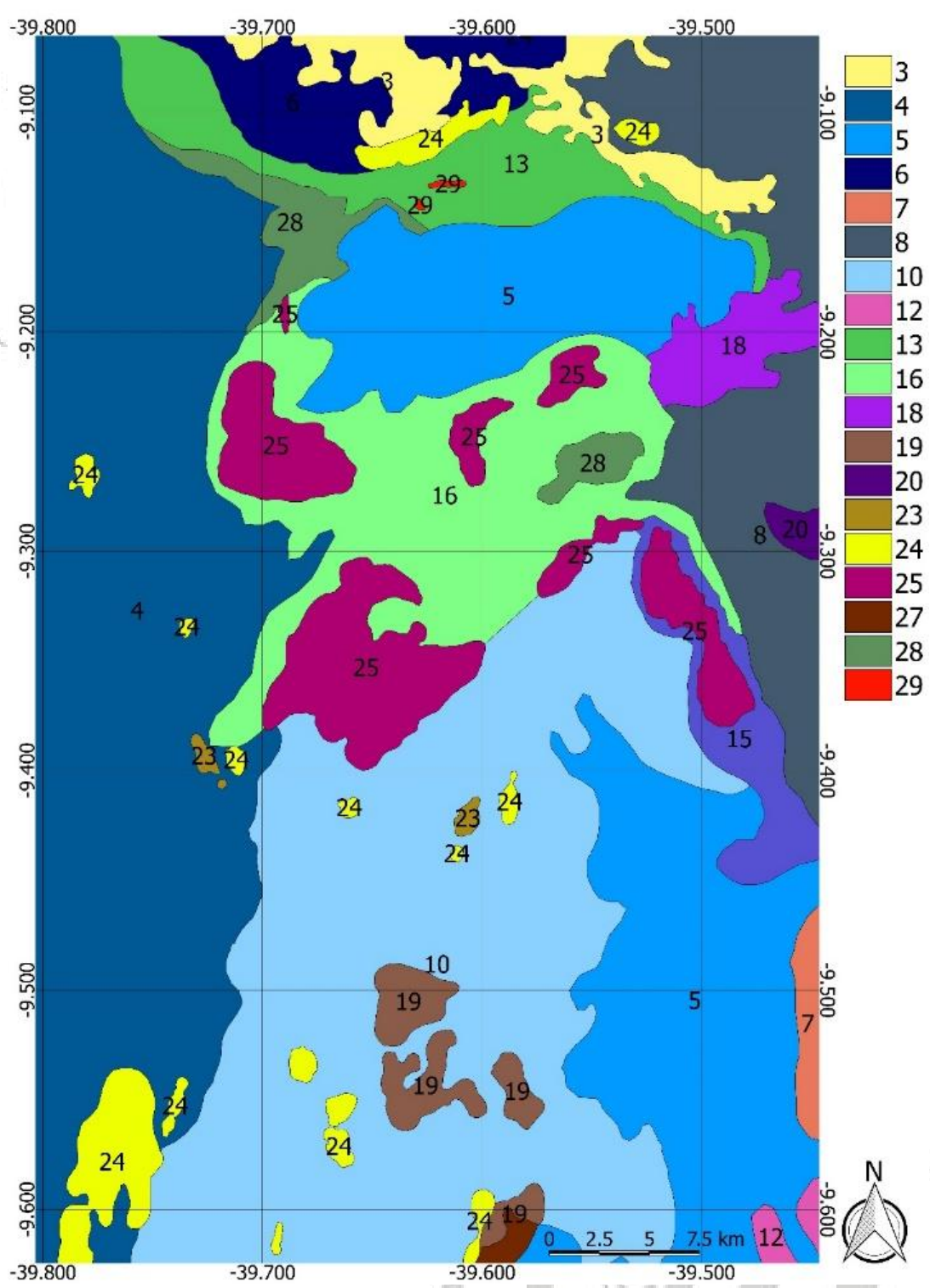

Figura 4: Fragmento do Mapa de Geossistemas do Município de Curaçá, Bahia. Para legenda ver o quadro na próxima página. 


\begin{tabular}{|c|c|c|c|c|}
\hline \multirow{2}{*}{\multicolumn{5}{|c|}{$\begin{array}{l}\text { DOMÍNIO DAS CAATINGAS } \\
\text { Caatinga dos Terrenos Rebaixados }\end{array}$}} \\
\hline & & & & \\
\hline \multicolumn{2}{|c|}{ Caatinga dos Terrenos Rebaixados do Embasamento Cristalino } & \multicolumn{3}{|c|}{ Caatinga dos Terrenos Sedimentares Rebaixados } \\
\hline $\begin{array}{l}\text { Caatinga dos Terrenos Rebaixados e } \\
\text { Pouco Acidentados do Embasamento } \\
\text { Cristalino }\end{array}$ & $\begin{array}{l}\text { Caatinga dos Terrenos } \\
\text { Rebaixados e Acidentados do } \\
\text { Embasamento Cristalino }\end{array}$ & \multicolumn{2}{|c|}{$\begin{array}{c}\text { Caatinga dos Terrenos Sedimentares Rebaixados e Pouco } \\
\text { Acidentados }\end{array}$} & $\begin{array}{c}\text { Caatinga dos Terrenos } \\
\text { Sedimentares Rebaixados e } \\
\text { Acidentados }\end{array}$ \\
\hline Caatinga de Pedimentos & Caatinga de Inselbergs & $\begin{array}{c}\text { Caatinga de Modelados de } \\
\text { acumulação }\end{array}$ & Caatinga de Glacis & $\begin{array}{l}\text { Caatinga de Testemunhos } \\
\text { Sedimentares }\end{array}$ \\
\hline $\begin{array}{l}3 \text { - Pedimentos dissecados com caatinga } \\
\text { florestada e arborizada em solos } \\
\text { argilosos e litólicos com afloramentos; } \\
4 \text { - Pedimentos com caatinga parque em } \\
\text { solos argilosos e litólicos com } \\
\text { afloramentos; } \\
5 \text { - Pedimentos com caatinga parque e } \\
\text { arborizada em solos argilosos e litólicos } \\
\text { com afloramentos; } \\
6 \text { - Pedimentos com caatinga florestada e } \\
\text { arborizada em solos argilosos e litólicos } \\
\text { com afloramentos; } \\
7 \text { - Pedimentos com caatinga arborizada, } \\
\text { parque, florestada e agropecuária em } \\
\text { solos argilosns e litólicns com } \\
\text { afloramentos; } \\
8 \text { - Pedimentos com caatinga arborizada, } \\
\text { parque e florestada em solos argilosos e } \\
\text { litólicos com afloramentos; } \\
10 \text { - Pedimentos com caatinga } \\
\text { arborizada e parque em solos argilosos e } \\
\text { litólicos com afloramentos; } \\
12 \text { - Pedimentos com caatinga } \\
\text { arborizada e florestada em solos } \\
\text { argilosos e litólicos com afloramentos. }\end{array}$ & $\begin{array}{l}23 \text { - Encostas com caatinga } \\
\text { arborizada, parque e rupestre em } \\
\text { solos litólicos ou pouco } \\
\text { desenvolvidos e afloramentos; } \\
24 \text { - Encostas com caatinga } \\
\text { arborizada, florestada e rupestre } \\
\text { em solos litólicos ou pouco } \\
\text { desenvolvidos e afloramentos. }\end{array}$ & $\begin{array}{l}18 \text { - Encostas suaves sob } \\
\text { caatinga parque e arborizada } \\
\text { em solos regoliticos; } \\
19 \text { - Encostas suaves sob } \\
\text { caatinga arborizada e parque } \\
\text { em cambissolos com ou sem } \\
\text { latossolos e argissolos; } \\
20 \text { - Encostas suaves sob } \\
\text { caatinga arborizada e } \\
\text { florestada em solos regolíticos; } \\
27 \text { - Encostas suaves sob } \\
\text { caatinga parque e arborizada } \\
\text { em cambissolos com ou sem } \\
\text { latossolos e argissolos. }\end{array}$ & $\begin{array}{l}13 \text { - Glacis com caatinga parque } \\
\text { e arborizada em solos argilosos, } \\
\text { litólicos e afloramentos; } \\
16 \text { - Glacis com caatinga } \\
\text { arborizada, florestada e rupestre } \\
\text { em solos argilosos, litólicos e } \\
\text { afloramentos; } \\
28 \text { - Glacis com caatinga parque } \\
\text { e arborizada em solos calcários } \\
\text { oxidados e afloramentos. }\end{array}$ & $\begin{array}{l}25 \text { - Encostas com caatinga } \\
\text { arborizada, florestada e rupestre } \\
\text { em solos calcários oxidados e } \\
\text { afloramentos; } \\
29 \text { - Encostas com caatinga } \\
\text { arborizada, florestada e rupestre } \\
\text { em solos litólicos ou pouco } \\
\text { desenvolvidos em rochas } \\
\text { sedimentares. }\end{array}$ \\
\hline
\end{tabular}

Quadro 1: Domínio das caatingas.

Até o presente momento a melhor representação cartográfica integrada do município era o mapa de unidades de paisagem e unidades geoambientais do Zoneamento Agroecológico do Nordeste (escala 1:2.000.000). Neste trabalho, Curaçá é representada como possuindo duas grandes unidades de paisagem: Superficies Cásrticas (J) e Depressão Sertaneja (F). Além disso, a Depressão 
Sertaneja é subdividida em quatro unidades geoambientais: F23 - Pediplanos do Sertão do São Francisco; F27 - Areais brancas; F29 - Áreas de relevo suave ondulado e predominantemente cascalhentas na calha do Rio São Francisco; F30 - Sertão do São Francisco. No município, as Superfícies Cársticas possuem apenas uma unidade denominada: Platôs do Salitre, Patamuté e Curaçá.

No Zoneamento Ecológico-Econômico da Bahia (1:5.500.000), o município de Curaçá é classificado como pertencendo ao Domínio Morfoestrutural das XI Depressões Interplanálticas Cristalinas, subdividido em quatro unidades geoambientais: 61 - Depressão Sertaneja de Curaçá; 62 - Depressão Sertaneja, ao sul do município e; 65 - Residuais nas Depressões Interplanálticas. Além destas, o domínio morfoestrutural I - Depósitos Sedimentares Recentes, marca o limite norte do município com a unidade geoambiental: 2 - Planície Fluvial do Rio São Francisco.

De um modo geral, as paisagens de Curaçá refletem uma organização natural associada à combinação de um clima semiárido quente atuando sobre rochas antigas e largamente afetadas por processos de aplanamento (Figura 5). Marcam a paisagem os mantos de intemperismo muito rasos ou ausentes, encostas tipicamente côncavas bordeadas por coluvionamentos, muitas vezes recobrindo ou sucedendo um tálus. 
Neste contexto, a vegetação de caatinga hiperxerófila predomina, contrastando formações rupestres com outras arborizadas, florestadas e parque. O terreno é drenado por canais de duas bacias da margem direita do Rio São Francisco, sendo uma delas o Rio Curaçá (que marca o limite leste do município) e a outra do Riacho da Vargem (limite oeste).

Geograficamente o município configura um interflúvio cujo aplanamento truncou principalmente rochas arqueanas com altitudes geralmente inferiores a $500 \mathrm{~m}$. Nestes pedimentos da porção mais distante dos canais do Curaçá e do Riacho da Vargem, predomina a caatinga arborizada, com elementos típicos como Cnidoscolus sp. (favela), Cenostigma pyramidale (catingueira), C. microphyllum (catingueira rasteira), Jatropha sp. (pinhão), Ziziphus joazeiro (juazeiro), Pseudobombax sp. (imbiruçú) e Commiphora leptophloeos (imburana).

Destaca-se a semelhança florística dominante em alguns inselbergs (ex. Serra da Natividade) com aquela apresentada em inselbergs de Petrolina (ex.: Serra da Santa), com destaque para Anadenanthera collubrina, Vellozia sp. e Cordia glabrata. 


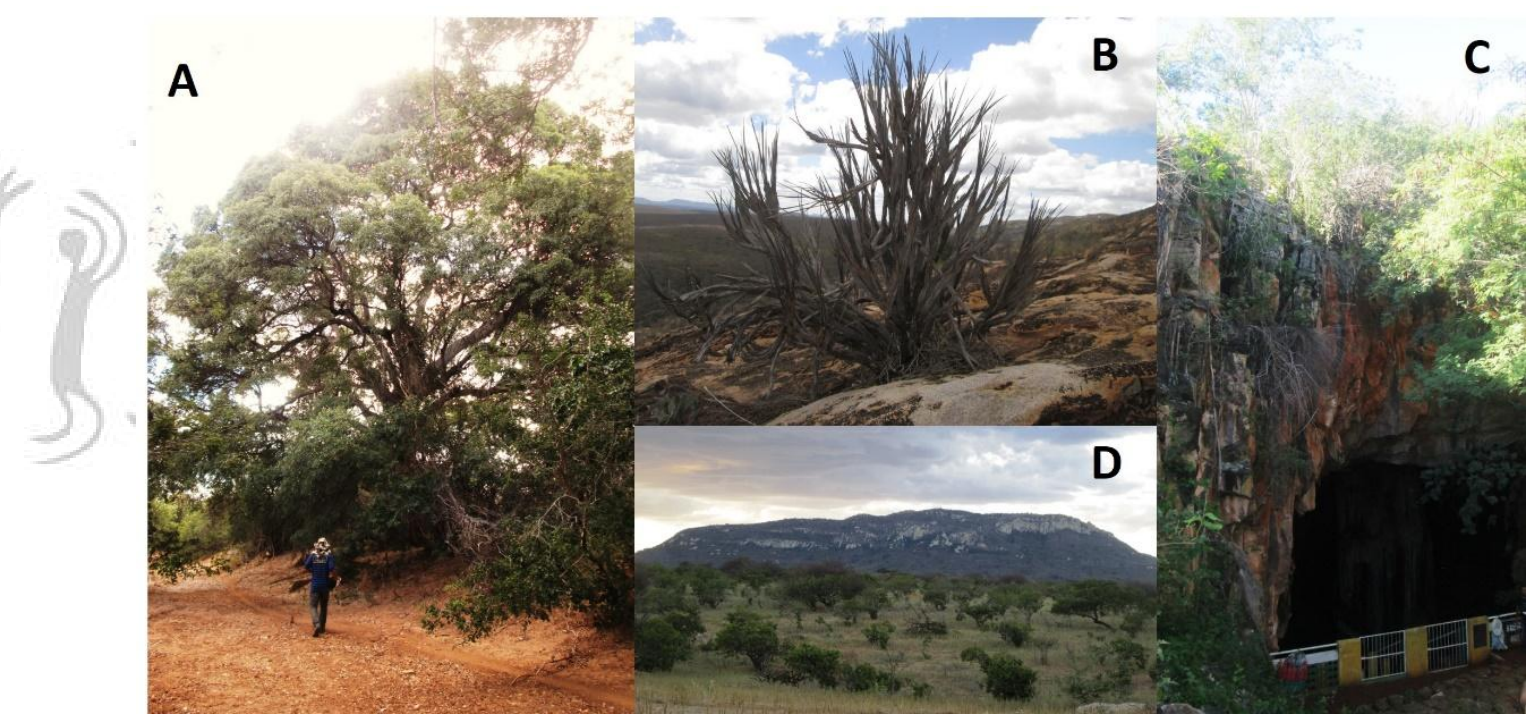

Figura 5: Aspectos das Paisagens de Curaçá. A - Canal intermitente e Braúna à direita; B - Detalhe de Vellozia sp. em lajedo; C - Entrada da Gruta de Patamuté; D - Serra da Natividade (ao fundo) e caatinga parque (primeiro plano).

A caatinga parque, acompanha áreas de maior ocupação humana nos pedimentos que truncam rochas metamáficas e metaultramáficas na margem direita do Rio Curaçá, ocorrendo também sobre o Filito Acauã ao sul da Serra da Natividade (Figura 5d). O fato de caatinga parque coincidir com as áreas de maior ocupação humana, permite a hipótese de que se trate de áreas em equilíbrio instável, resultantes da recomposição da vegetação original pelo desmate e posterior abandono das terras.

Ainda nos pedimentos, desta vez ao norte da Serra da Natividade ocorre uma mancha de caatinga florestada sobre os xistos do Grupo Macururé que tem quase 
vezes o tamanho do município do Recife. Esta área conta com espécies bem preservadas, a exemplo de Schinopsis brasiliensis (Braúna) e Tabebuia caraiba (Caraibeira) (Figura 5a).

O aplanamento é interrompido na área dos maciços com dissecação controlada por zonas de cisalhamento com direção NW-SE que afetam os ortognaisses e paragnaisses do Complexo Sobradinho-Remanso na porção centro norte do município. Neste local as altitudes superam os 700m (Serras do Escovão, do Olho d'água e das Campinas).

Além disso, intercaladas às rochas arqueanas ocorrem intrusões neoproterozoicas que por vezes formam inselbergs (Serras da Natividade e da Capivara), além de cristas quartzíticas (Serras do Exu e dos Campos Novos). É comum que tanto os inselbergs quanto as cristas apresentem altitudes entre $500 \mathrm{~m}$ e $700 \mathrm{~m}$.

Nas áreas de relevos acidentados, é comum a caatinga arborizada principalmente com Anadenanthera colubrina (angico-de-caroço), sendo comuns Cordia glabrata e Sapium sp.. Esta caatinga arborizada dos inselbergs, cristas e maciços é comumente intercalada com caatinga rupestre nos lajedos dominados por bromélias (principalmente Encholirium spectabile - macambira-de-flecha), diferentes gêneros de cactos (Melocactus, Facheiroa, Pilosocereus) e Vellozia sp. (Figura 5b). 
A altitude cai gradualmente até $350 \mathrm{~m}$ nos canais do Rio Curaçá e Riacho da Vargem, chegando a 320 na margem do Rio São Francisco (norte). Nas planícies e terraços aluviais, do São Francisco, a agricultura irrigada ocorre, ainda que de forma tímida.

As rochas arqueanas supracitadas estão encimadas por filitos e metacarbonatos do Neoproterozoico que formam glacis. Os metacarbonatos especificamente estruturam testemunhos que superam $650 \mathrm{~m}$ na porção central do município, chegando a altitudes superiores a 850 metros na Serra da Borracha. Nos metacarbonatos da Serra da Gruta está localizada a Gruta de Patamuté (Figura 5c). Nesta localidade a caatinga arborizada e parque são comuns.

Considerando os mapas anteriores (Figura 6), o trabalho inova em nível de detalhamento da representação da estrutura paisagística. Este novo mapa, traz a unidade de Glacis, modelado de aplanamento em rochas sedimentares (THOMAS, 1994) que não que não havia sido mencionada nos trabalhos anteriores. A diferenciação entre inselbergs e cristas quartzíticas também é um destaque. 

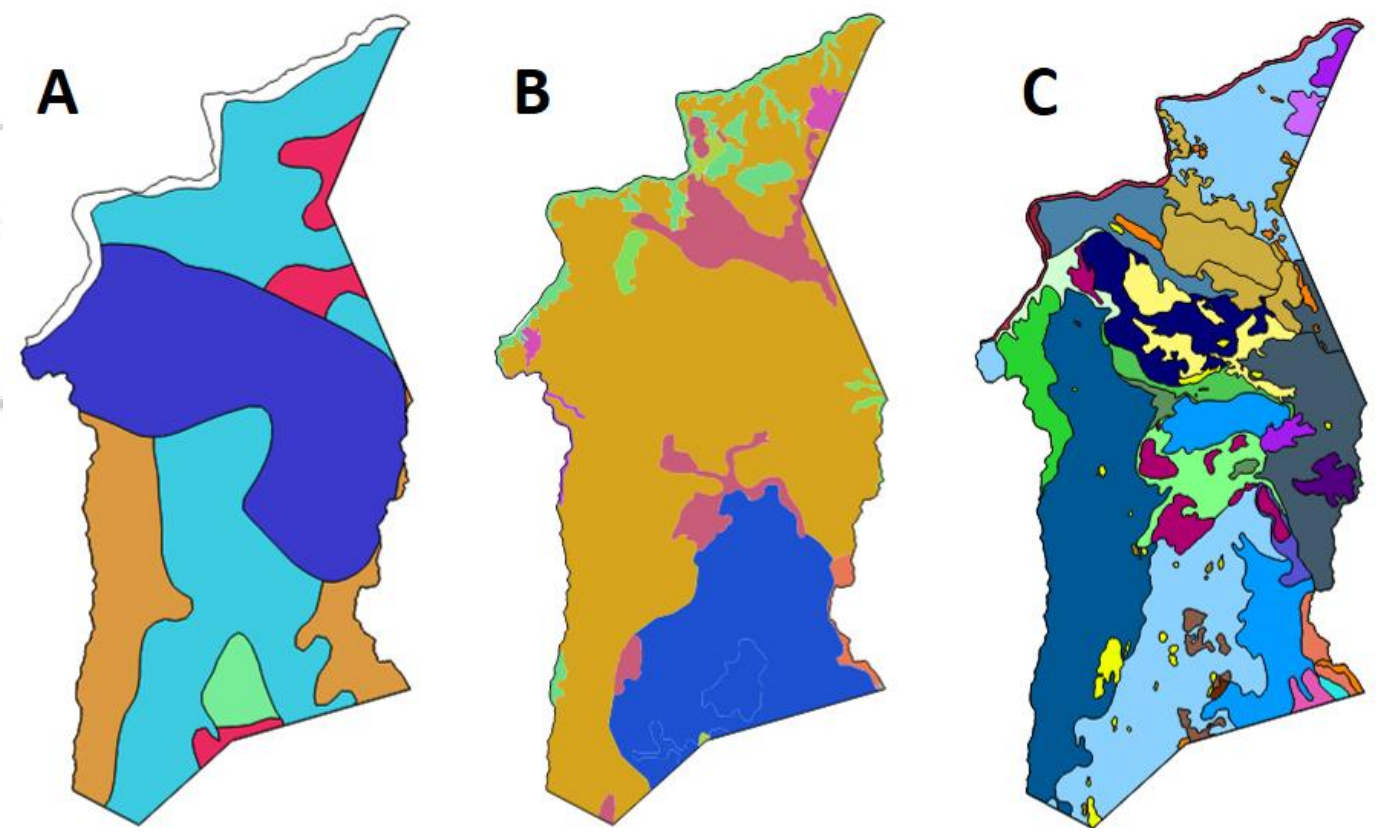

Figura 6: Comparação dos Mapas Geoambientais disponíveis para Curaçá. A EMBRAPA; B - ZEE/BA; C - Este trabalho.

Além disso, a abordagem upscaling, implementada por meio da aglutinação de grupos de fácies com referência principalmente às unidades geomorfológicas, permitiu guardar a precisão dos limites das unidades inferiores para as categorias de geossistemas superiores. Isto permite ao planejador reduzir o detalhamento das categorias sem sacrificar a precisão dos limites das unidades (Figura 7). 

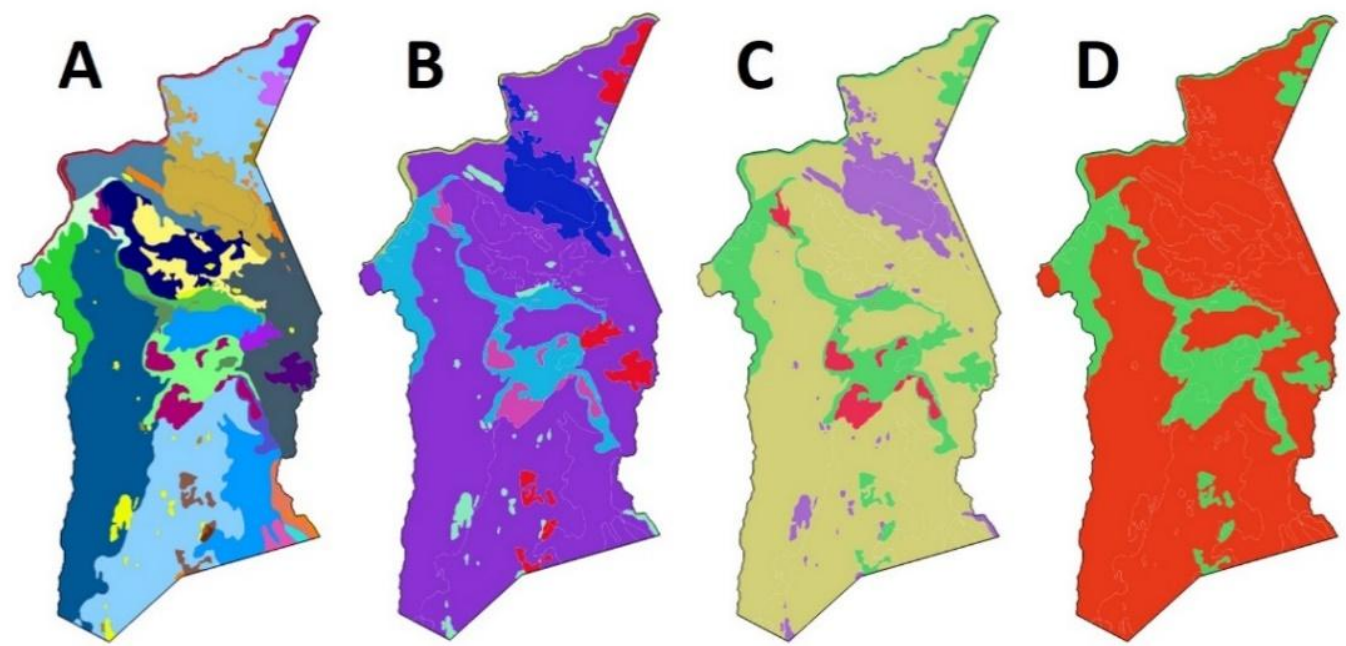

Figura 7: Diferentes Categorias de Geossistemas Mapeados. A - Grupos de fácies; B Classes de fácies; C - Subgrupo de Paisagem; D - Grupos de Paisagens.

\section{CONSIDERAÇÕES FINAIS}

Este trabalho caracterizou de modo geral a estrutura das paisagens do município de Curaçá a um nível de detalhamento inovador em relação aos estudos anteriores. Espera-se que o mapa apresentado seja útil aos estudos paleoambientais, tanto quanto ao planejamento de uso da terra do município em questão.

O método de aglutinação dos grupos de fácies em geossistemas de categorias superiores mostrou-se bastante útil, sobretudo por guardar a qualidade dos limites das unidades nos níveis superiores. 
Infelizmente, o detalhamento e refinamento dos grupos ainda é necessário. Nenhuma informação foi dada sobre os geossistemas nos ambientes fluviais, nem de ambientes lênticos. Estudos posteriores devem se basear num recobrimento de campo sistemático, mormente com vistas ao detalhamento dos grupos de fácies já reconhecidos, além de avaliar a pertinência das classes de solos e vegetação indicadas.

Em função do tamanho do município, áreas indicadas para iniciar um levantamento sistemático e detalhado dos geossistemas são àquelas propostas para criação das unidades de conservação estaduais e federais.

\section{REFERÊNCIAS BIBLIOGRÁFICAS}

BAHIA. Zoneamento Ecológico-Econômico da Bahia. Disponível em: http://www.zee.ba.gov.br/zee/ acesso em 26 nov 2016.

BAILEY, R.G. Ecosystem Geography: From Ecoregions to Sites. 2ed. New York: Springer. 2009. 251p.

BRIERLEY, G.J.; FRYIRS, K.A. Geomorphology and River Management: Applications of the River Styles Framework. Blackwell Publishing, Oxford, UK, 2005. 398p.

CAVALCANTI, L.C.S. Geossistemas do Semiárido Brasileiro: Considerações Iniciais. Caderno de Geografia (PUC-Minas). Edição especial do III Simpósio de Geografia Física do Nordeste. 2016. v.26. n.2. p.214-228.

CAVALCANTI, L.C.S.; CORRÊA, A.C.B. Da descrição de áreas às sínteses naturalistas: uma abordagem historiográfica sobre a ideia de 'áreas naturais'. Espaço e Geografia (UNB). v.17 n.2. 2014. p.377-422. 
CAVALCANTI, L.C.S.; CORRÊA, A.C.B. Geossistemas e Geografia no Brasil. Revista Brasileira de Geografia. v.61.n.2. 2016. p.3-33.

CAVALCANTI, L.C.S.; LIRA, D.R.; CORRÊA, A.C.B. Tipologia de Geoformas para Cartografia de Detalhe no Semiárido Brasileiro. XVI Simpósio Nacional de Geomorfologia. Maringá. 2016. 8p.

CHRISTIAN, C.S., STEWART, G.A. General report on survey of Katherine-Darwin Region, 1946. Melbourne: CSIRO. Land Research Series. No. 1. 1952. 177p.

CORREA, A.C.B. O geossistema como modelo para a compreensão das mudanças ambientais pretéritas: uma proposta de geografia física como ciência histórica. In: Sá, A.J. \& CORREA, A.C.B. Regionalização e análise regional. Perspectivas e abordagens contemporâneas. Recife: Editora Universitária da Universidade Federal de Pernambuco, 2006, p. 33-45.

CORREA, A.C.B.; SOUZA, J.O.; CAVALCANTI, L.C.S. Solos do ambiente semiárido brasileiro: erosão e degradação a partir de uma perspectiva geomorfológica. In: GUERRA, A.J.T.; JORGE, M.C.O. Degradação dos Solos no Brasil. Rio de Janeiro: Bertrand Brasil. 2014. p.127-166.

ECOSSISTEMA. Proposta para criação de um mosaico de unidades de conservação no município de Curaçá, Bahia: Subsídios para a criação de um mosaico de unidades de conservação no município de Curaçá, Bahia. Disponível em: http://www.inema.ba.gov.br/wp-content/uploads/2013/08/Produto-7-

Relat\%C3\%B3rio-S\%C3\%ADntese_Mosaico-de-UCs_24jul2013.pdf acesso em 26 nov 2016.

FERREIRA JUNIOR, W. G.; CAVALCANTI, L. C. S.; LYRA, L. H. B.. Cartografia das Paisagens da Serra da Natividade (Curaçá-BA): Subsídios à Conservação do Patrimônio Natural do Semiárido Brasileiro. In: Anais do XVI Simpósio Brasileiro de Geografia Física Aplicada, 2015.

IBGE. Manual Técnico da Vegetação. Rio de Janeiro: IBGE. 2007. 
ISACHENKO, G.A. Long-term conditions of Taiga landscapes of European Russia. In: DYAKONOV, K.N., KASIMOV, N.S., KHOROSHEV, A.V., KUSHLIN, A.V. Landscape Analysis for sustainable development: theory and applications of landscape science in Russia. Moscou: Alexplublishers, 2007. p.144-155.

KHOROSHEV, A.V. Multilevel analysis of landscape structure for land use decisions. In: BARANČOKOVÁ, M.; KRAJČÍ, J.; KOLLÁR, J.; BELČÁKOVÁ, I. (ed.) Landscape Ecology: Methods, Applications and Interdisciplinary Approach. Bratislava: ILE. 2010. 99-112p.

LYSANOVA, G.I.; SEMENOV, Y.M.; SOROKOVOI, A.A. Geosystems of the Upper Yenisei Basin. Geography and Natural Resources. 2011, Vol. 32, No. 4, p. 9299.

MEIADO, M.V.; ROJAS-ARÉCHIGA, M.; SIQUEIRA-FILHO, J.A.; LEAL, I.R. Effects of light and temperature on seed germination of cacti of Brazilian ecosystems. Plant Species Biology. v.31. n.2. 2015. p.87-97.

MINISTÉRIO DO MEIO AMBIENTE. Diretrizes Metodológicas para o Zoneamento Ecológico-Econômico do Brasil. Brasília: MMA. 2006.

SOCHAVA, V.B. Introdução à Teoria do Geossistema. Novasibéria, Nauka, 1978. 320p. Em russo

SOCHAVA, V.B. O estudo de geossistemas. Métodos em questão, n.16, IGUSP. São Paulo, 1977. $51 \mathrm{p}$.

SUVOROV, E.G.; SEMENOV, Y.M.; ANTIPOV, A.N. Concept of landscape information renovation for Siberia area. In: DYAKONOV, K.N., KASIMOV, N.S.,

KHOROSHEV, A.V., KUSHLIN, A.V. Landscape Analysis for sustainable development: theory and applications of landscape science in Russia. Moscou: Alexplublishers, 2007. p.80-92.

THOMAS, M.F. Geomorphology in the tropics: a study of weathering and denudation in low latitudes. Chichester: John Wiley \& Sons. 1994. 460p. 


\section{Clio Arqueológica 2017, V32N3, p.61-87, CAVALCANTI. \\ DOI: 10.20891/clio.V32N3p61-87}

TRICART, J. Ecodinâmica. Rio de Janeiro, FIBGE/SUPREN. 1977. 91p.

VERSTAPPEN, H.T.H. Remote sensing in geomorphology. Amsterdam: Elsevier. 1977. 214p.

ZUCHKOVA, V.K.; RAKOVSKAIA, E.M. Métodos de Investigação em Geografia Física Integrada. Moscou: Academiia. 2004. 368p. em russo. 